\title{
Puentes que unen y muros que separan. Fronterización, securitización y procesos de cambio en las fronteras de México y Brasil
}

\section{United by bridges, divided by walls. Borderization, securitization and change in the Mexican and Brazilian borders}

\begin{abstract}
Carlos Samuel Ibarra Ramírez https://orcid.org/0000-0002-9099-9238

El Colegio de la Frontera Norte, México

Reseña:

cs.ibarra@live.com

Hernández Hernández, Alberto (coord.). (2020). Puentes que unen y muros que separan: fronterización, securitización y procesos de cambio en las fronteras de México y Brasil. Tijuana, México/Brasil: El Colegio de la Frontera Norte/Universidade Federal de Mato Grosso do Sul (UFMS), pp. 368, ISBN: 978-607-479-359-7
\end{abstract}

Resumen:

El objetivo de la obra reseñada es hacer un análisis comparativo entre las fronteras de Brasil y la de México-Estados Unidos. Se enfoca en los procesos de securitización que se han dado a lo largo de las últimas décadas y que han impactado en la capacidad de tránsito y flujo a través de dichas fronteras, y también en la calidad de vida de las personas y las regiones aledañas a estas franjas fronterizas. En términos metodológicos, la información de cada apartado se nutre de la investigación bibliográfica y, sobre todo, de datos etnográficos, los cuales son producto del trabajo de campo realizado. El resultado de esta combinación es una serie de reflexiones actualizadas con respecto al estado presente de las dinámicas fronterizas en el norte y en el sur del continente. Se llega, además, a un conjunto de conclusiones que demuestran que el incremento en la securitización y en la fronterización de ambas regiones tiene que ver con un Estado cada vez más restrictivo y cauteloso contra la otredad.

Palabras clave: muro fronterizo, flujos, movilidades transfronterizas, desarrollo, xenofobia

\section{Abstract:}

This book makes a comparative analysis between the Brazilian borders and the Mexico-US border. It focuses on the processes of border securitization that have been implemented throughout recent decades that have impacted the capacity to cross borders and border flows, as well as the quality of life of the people and regions in the borderlands. Methodologically speaking, the information about these topics is based on bibliographic research and, particularly, ethnographic data emerging from the fieldwork conducted. The combination of these two methods produced a series of up-to-date reflections regarding the current state of the border dynamics in the north and south of the American continent. The conclusions demonstrate that an increase in border securitization and border crossing in both regions is related to a State that is increasingly restrictive and cautious about the Other.

Key words: Border wall, flows, transborder mobility, development, xenophobia 
Puentes que unen y muros que separan.

Fronterización, securitización y procesos de cambio en las fronteras de México y Brasil

CARLOS SAMUEL IBARRA RAMÍREZ

D

urante las últimas dos décadas, la injerencia del Estado en las dinámicas socioculturales de las regiones fronterizas se ha incrementado de manera considerable. Algunas de las formas en como esto se ha dado tienen que ver con la complejización de los procesos de fronterización y securitización ocurridos en las diferentes fronteras del mundo. En el caso particular del libro Puentes que unen y muros que separan: fronterización, securitización y procesos de cambio en las fronteras de México y Brasil (Hernández, 2020), el foco de atención recae en las fronteras de ambos países, logrando, a su vez, recopilar distintas experiencias desde una perspectiva multidisciplinar: la antropología, la sociología y la geografía, principalmente.

Es un hecho que, con el paso del tiempo, las fronteras de ambos países han sofisticado sus mecanismos de filtración y contención, haciendo de ellas baluartes cada vez más difíciles de penetrar por las personas no autorizadas por el aparato estatal. Sin embargo, como se podrá apreciar en los capítulos de esta obra, las fronteras son habitadas por personas con agencia. Este elemento permite la negociación y generación de estrategias, recursos simbólicos, discursivos y materiales que dinamizan la vida en los límites del Estado. Es importante mencionar que esta compilación no destaca por sus aportaciones teóricas; no obstante, esto no demerita su contenido empírico y metodológico. Así, el libro abre con una introducción por parte del sociólogo Alberto Hernández y la geógrafa Adriana Dorfman. Esta introducción sirve como estado del arte en lo tocante a los estudios sobre fronteras y permite establecer una referencia contextual para enmarcar los debates presentes en la totalidad de los capítulos que conforman la obra. Además, permite reflexionar sobre la securitización y la fronterización, dos temas ciertamente novedosos.

En cuanto al contenido capitular, el libro se divide en tres secciones temáticas. La primera se titula Las fronteras que nos unen. Está dedicada a la conceptualización y definición de terminología comúnmente utilizada en el estudio de las regiones fronterizas. Tal es el caso del capítulo «Fronteras y escalas», a cargo del geógrafo Alejandro Benedetti, en el cual se discute a profundidad el debate sobre los tipos de categorizaciones y las diferentes perspectivas escalares que implica el estudio de las fronteras.

Por su parte, Amalia Campos-Delgado, desde una perspectiva antropológica y política, escribe sobre «Sistemas de control fronterizo: in-seguridad, sospecha e intuición». La autora centra la discusión en los sistemas de control fronterizo y el impacto que estos han tenido para las personas que transitan por las fronteras. 
Puentes que unen y muros que separan.

Fronterización, securitización y procesos de cambio en las fronteras de México y Brasil

CARLOS SAMUEL IBARRA RAMÍREZ

La segunda sección, México y sus regiones fronterizas, abre con la aportación sociológica de Alberto Hernández: «La ciudad de Tijuana en el escenario fronterizo: interacciones y procesos de cambio en la frontera noroeste de México». Aquí se narra el rol de Tijuana como la frontera terrestre más activa del mundo y los cambios que está ha sufrido durante las últimas décadas en términos de flujos, crecimiento e interacción.

Aún con la mirada en la frontera México-Estados Unidos, el capítulo del geógrafo Xavier Oliveras González, «La fronterización y desfronterización del río Bravo/Grande», explica cómo un elemento natural y aparentemente inerte -un río- ha sido utilizado y desarrollado como barrera a raíz de los diversos procesos de securitización.

Los siguientes dos capítulos nos trasladan a la frontera México-Guatemala: Jessica Nájera escribe «La frontera México-Guatemala: un espacio de movilidades y migraciones poblacionales desde una perspectiva demográfica». Describe con lujo de detalle los flujos migratorios guatemaltecos. Su información resulta útil para conocer y comprender el contexto social, económico y político que condiciona las interacciones que ocurren en la frontera sur de México.

El siguiente capítulo se titula «La frontera México-Guatemala en el prisma de las fronteridades (borderities) múltiples: un acercamiento preliminar», escrito por la politóloga Edith Kauffer, quien propone un análisis desde la propuesta epistemológica de las borderities, no sin antes revisar la discusión de otros conceptos precursores, tales como border, frontier y boundary.

La tercera sección de este libro se titula Brasil y sus regiones fronterizas, y cuenta con cinco capítulos. El primero de ellos es «Viejos hábitos nunca mueren: el dilema entre seguridad y desarrollo en las políticas públicas para la frontera», escrito por los geógrafos Rebeca Steiman y Licio Caetano do Rego Monteiro. Estos autores proponen un análisis contextual y político de la frontera brasileña a partir de tres puntos importantes en su historia: el periodo de la dictadura militar, el de la integración regional y el del Plan Estratégico de Fronteras. El siguiente capítulo es «Visión global de la frontera argentino-brasileña». Está a cargo de Alejandro Benedetti y Alejandro Rascovan, quienes unen su expertise geográfica y sociológica en la contextualización y descripción de las dinámicas fronterizas Brasil-Argentina. Dada la extensión territorial brasileña, los siguientes tres capítulos retoman otras fronteras. Por su parte, «El espacio urbano transfronterizo y trinacional: una aproximación a las triples fronteras entre Foz do Iguaçu (BR)/Ciudad del Este (PY)/Puerto Iguazú (AR) y Tabatinga (BR)/Leticia 
Puentes que unen y muros que separan.

Fronterización, securitización y procesos de cambio en las fronteras de México y Brasil

(CO)/Santa Rosa (PER)», escrito por el sociólogo José Lindomar C. Albuquerque, es un esfuerzo por narrar las características y las diferencias entre los puntos de cruce en dos triples fronteras: Brasil-Paraguay-Argentina y Brasil-Colombia-Perú. En una línea similar, las aportaciones del geógrafo Edgar Aparecido da Costa, en su capítulo «Corumbá en la frontera Brasil-Bolivia: entre aproximaciones y distanciamientos», brinda luz para un caso pocas veces estudiado. Finalmente, con el propósito de abordar la frontera franco-brasileña, la mirada socioantropológica de Jania Perla Diógenes de Aquino y Joana Domingues Vargas, en «Mineros clandestinos en Guyana Francesa», permite apreciar las dinámicas y estrategias que las personas desarrollan al interior de las economías legales e ilegales que operan en esta región.

Este libro representa una importante contribución para la presentación general de las realidades fronterizas, no solo para quienes buscan iniciar estudios sobre el tema, sino también para el público en general. Así, por medio de un extenso trabajo de campo e información empírica, los autores encaran el reto de explicar la complejidad de los escenarios presentes en las fronteras de estos dos extensos y poblados países. Ambos son referentes para el continente. Poseen, además, importantes fronteras simbólicas, históricas, culturales e identitarias. No olvidemos que la frontera México-Estados Unidos representa también un choque entre Latinoamérica y el mundo anglosajón, así como una auténtica línea divisoria entre el primer mundo y los países en el eterno desarrollo. De manera similar, las fronteras entre los países sudamericanos y Brasil son barreras simbólico-culturales entre el mundo hispanoparlante y lusófono. Si bien no son tan diferentes en linaje, sí obedecen a dinámicas históricas, geográficas y sociales distintas.

Al ser una compilación, este libro contiene los resultados de diversas investigaciones con distintas aproximaciones teórico-metodológicas y, aunque esto podría parecer una debilidad, el resultado es una visión panorámica de las diversas dinámicas transfronterizas en el continente. El debate importante que se pone sobre la mesa, desde luego, se relaciona con los procesos de fronterización y securitización que han ocurrido durante las últimas décadas. Sin embargo, algunos autores dan pistas sobre las formas cada vez más complejas de exclusión y seguridad. Así sucede con la información biométrica contenida en los documentos de identidad y visas que existen para cruzar a los Estados Unidos y que, seguramente, serán emuladas por los demás países conforme evolucionen sus mecanismos de seguridad y militarización fronteriza. Esta situación conlleva no solo una mayor precarización de quienes buscan atravesar estas fronteras sin 
documentos oficiales, sino un incremento potencial en los tipos de violencia y discriminación ejercidos en estos contextos. Otro aporte importante de esta obra radica en los esfuerzos por describir la capacidad de agencia humana. Es decir, se explican las estrategias cotidianas y extraoficiales que permiten a las personas sobrevivir en este tipo de contextos. Asimismo, se habla de la aparición de las economías y flujos de lo ilegal, de lo ilícito y del contrabando, pues estos no tienen, necesariamente, una connotación criminal o delictiva.

Comparar fronteras no es un proceso sencillo en lo teórico, metodológico o logístico. De ahí que existan pocos trabajos que se dediquen a realizar esta tarea. No obstante, este es un motivo que vuelve novedosa la propuesta de esta obra. Más allá de las debilidades que esta compilación pudiera tener en términos de consistencia capitular (algo difícil considerando la multiplicidad de enfoques y de autores) sí es un avance importante en la literatura sobre las fronteras en Latinoamérica. Sobre todo por el aporte que los datos empíricos, en cada uno de los capítulos, representan por sí mismos.

\section{Cómo citar este artículo:}

Ibarra Ramírez, Carlos S. (2021), Puentes que unen y muros que separan. Fronterización, securitización y procesos de cambio en las fronteras de México y Brasil. Revista Pueblos y fronteras digital, 16, e-574, doi: https//doi.org/10.22201/cimsur.18704115e.2021.v16.574 